\title{
UMA NOVA COMPREENSÃO DOS DIREITOS HUMANOS NA CONTEMPORANEIDADE A PARTIR DOS OBJETIVOS DE DESENVOLVIMENTO SUSTENTÁVEL (ODS)
}

\author{
Vladmir Oliveira da Silveira* \\ Taís Mariana Lima Pereira**
}

SUMÁRIO: Introdução; 2 A Historicidade dos direitos bumanos; 3 Direitos bumanos na contemporaneidade; 4 Objetivos de desenvolvimento sustentável; 5 Os objetivos de desenvolvimento sustentável como reflexo dos direitos bumanos na contemporaneidade; 6 Conclusão; Referências.

RESUMO: O presente trabalho destina-se a averiguar se os 'Objetivos de Desenvolvimento Sustentável' (ODS), parte integrante da Agenda 2030 da Organização das Nações Unidas (ONU), podem refletir uma nova compreensão dos direitos humanos na contemporaneidade. Para a realização dessa análise são traçadas considerações sobre a historicidade dos direitos humanos e sobre tais direitos na contemporaneidade, com breves apontamentos sobre a divergência entre as doutrinas universalista e relativista, a nova concepção multiculturalista e o atual foco de atenção aos direitos humanos: sua efetividade e proteção. Também são abordados os aspectos essenciais dos ODS e da Agenda 2030, utilizando-se de dados oficiais da ONU. Ao final, se responderá ao problema inicialmente proposto, com o intuito de verificar se os ODS efetivamente podem ser considerados como reflexo de uma nova compreensão dos direitos humanos no mundo contemporâneo. O trabalho utiliza-se do método dedutivo, a partir de pesquisas em referenciais bibliográficos, tratados internacionais sobre a matéria e dados estatísticos da ONU.

PALAVRAS-CHAVE: Direito Internacional dos Direitos Humanos; Organização das Nações Unidas; Objetivos de Desenvolvimento Sustentável (ODS); Agenda 2030; Desenvolvimento Sustentável; Sustentabilidade.

\footnotetext{
Advogado; Pós-doutor em Direito pela Universidade Federal de Santa Catarina (UFSC). Docente Titular da Universidade Federal de Mato Grosso do Sul (UFMS) e Docente da Pontifícia Universidade Católica de São Paulo (PUC/SP). E-mail: vladmiracademico@gmail.com

*** Advogada. Especialista em Direito Administrativo pelo Instituto de Direito Romeu Felipe Bacellar, Curitiba (PR), Brasil.
} 


\title{
A NOVEL AND CONTEMPORARY COMPREHENSION OF HUMAN RIGHTS FROM THE AIMS OF SUSTAINABLE DEVELOPMENT (ASD)
}

\begin{abstract}
Current analysis discusses whether the Aims of Sustainable Development (ASD), an integral part of Agenda 2030 of UN may provide a novel and current understanding on human rights. The historicity of human rights and their current role are investigated, coupled to brief notes on the divergence between the universalistic and relativist doctrines, the new multicultural concept and current focus on human rights: their efficaciousness and protection. The essential aspects of ASD and of Agenda 2030 are underscored with UNO official data. The initial issue is tackled to verify whether ASD may effectively be a reflection of a new understanding of Human Rights in current conditions. The deductive method is foregrounded on research retrieved from bibliographical databases, international treaties on the issue and UNO statistics.
\end{abstract}

KEY WORDS: International Right of Human Rights; UN; Aims of Sustainable Development (ASD); Agenda 2030; Sustainable development; Sustainability.

\section{UNA NUEVA COMPRENSIÓN DE LOS DERECHOS HUMANOS EN LA CONTEMPORANEIDAD A PARTIR DE LOS OBJETIVOS DE DESARROLLO SOSTENIBLE (ODS)}

RESUMEN: El presente estudio se destina a averiguar si los 'Objetivos de Desarrollo Sostenible' (ODS), parte integrante de la Agenda 2030 de la Organización de las Naciones Unidas (ONU), pueden reflejar una nueva comprensión de los derechos humanos en la contemporaneidad. Para la realización de ese análisis se trazan consideraciones sobre la historicidad de los derechos humanos y sobre estos derechos en la contemporaneidad, con breves apuntes sobre la divergencia entre las doctrinas universalista y relativista, la nueva concepción multiculturalista y el actual enfoque de atención a los derechos humanos: su efectividad y protección. También se abordan los aspectos esenciales de los ODS y de la Agenda 2030, utilizándose de datos oficiales de la ONU. Al final, se contestará al problema inicialmente propuesto, con el intuito de verificar si los ODS efectivamente pueden ser considerados como reflejo de una nueva comprensión de los derechos humanos en el mundo contemporáneo. En el estudio se utiliza del método deductivo, a partir de investigaciones en referenciales bibliográficos, tratados internacionales sobre la materia y datos estadísticos de la ONU.

PALABRAS CLAVE: Derecho Internacional de los Derechos Humanos; Organización de las Naciones Unidas; Objetivos de Desarrollo Sostenible (ODS); Agenda 2030; Desarrollo Sostenible; Sustentabilidad. 


\section{INTRODUÇÃO}

Os direitos humanos sempre foram motivo de grandes discussões políticas, filosóficas e jurídicas. Muito já se debateu acerca da sua fundamentação, validade e abrangência. No entanto, atualmente a maior controvérsia em relação aos direitos humanos diz respeito à sua efetividade e proteção.

Desde a Declaração Universal dos Direitos Humanos de 1948, marco inicial do que se concebeu por direitos humanos na contemporaneidade, a humanidade já desenvolveu um longo e frutífero caminho no sentido de reconhecer universalmente alguns direitos e adotar medidas em prol de seu resguardo. Porém, ainda há muito a ser feito.

As pesquisas e estatísticas demonstram que vivemos num mundo extremamente desigual. Nesse cenário no qual a riqueza está concentrada nas mãos de poucos indivíduos e países, existem milhões de pessoas vítimas de infortúnios de violações aos direitos humanos. São seres humanos que ainda não têm acesso em seu cotidiano aos mais básicos recursos para uma vida digna: água potável, saneamento básico e energia elétrica. Muitos desses indivíduos passam rotineiramente por situações de fome, não possuem uma moradia segura ou vivem em áreas de conflito, estão completamente desassistidos de cuidados médicos, não possuem acesso à educação básica nem auxílio das instituições governamentais. Tratam-se de milhões, talvez bilhões, de pessoas para quem os direitos humanos ainda não se fizeram sentir.

Paralelamente a esse perturbador contexto social e econômico, os desafios ambientais também continuam gigantescos e, infelizmente, não param de crescer. Diversas espécies da fauna e da flora foram extintas ou estão ameaçadas de extinção em razão da degradação dos ecossistemas ou de práticas predatórias desenfreadas. É certo que a sociedade de consumo gera milhões de toneladas de lixo que são despejadas diariamente no planeta, além do aquecimento global que continua a aumentar e contribuir com severas mudanças climáticas, as quais seguem causando verdadeiras catástrofes. É nesse cenário que surgem os Objetivos de Desenvolvimento Sustentável (ODS), no âmbito da Organização das Nações Unidas (ONU). Com efeito, será discutido de modo pormenorizado no decorrer deste trabalho, se os ODS correspondem a uma reafirmação dos Estados-membros da ONU em relação à importância e a validade dos direitos humanos previstos em diversos tratados internacionais e declarações sobre a matéria, abordando soluções de viés prático a 
partir do estabelecimento de objetivos e metas com prazo para cumprimento.

Apesar de por vezes a realidade parecer desoladora, não se pode deixar de lado o impulso transformador que moveu a humanidade até os dias atuais e que nos trouxe até aqui. É com esse espírito de mudança, no sentido aristotélico do imperfeito para o perfeito, que devem ser analisados os ODS, como uma ratificação dos ideais dos direitos humanos e como um possível caminho para sua plenitude. Nessa perspectiva, utilizar-se-á da Dinamogenesis dos Direitos Humanos como referencial teórico.

Para abordar a problemática que envolve os direitos humanos na contemporaneidade e o significado dos ODS nesse contexto global multifacetado o presente trabalho utilizará do método dedutivo, a partir de pesquisas em referenciais bibliográficos, tratados internacionais sobre a matéria e dados estatísticos da ONU.

\section{A HISTORICIDADE DOS DIREITOS HUMANOS}

A fundamentação do que hoje se concebe por direitos humanos sempre foi um campo fértil de debates e divergências jusfilosóficas, remontando suas origens ao período axial (séculos VIII a II a.C.) ${ }^{03}$ em que pese a noção de universalidade de tais direitos seja extremamente recente na história. ${ }^{04}$

O fundamento último dos Direitos Humanos é a dignidade da pessoa. Para o jusnaturalismo medieval, o caráter pessoal era o que determinava que o homem fosse a imagem e semelhança de Deus. O entendimento predominante do jusnaturalismo moderno, por outro lado, é o de que esse caráter está na peculiar existência do homem como ser racional, com possibilidade de realizar-se igualitária, livre e solidariamente junto aos demais seres humanos. Ser uma pessoa, portanto, não é só dispor de si mesmo, mas dispor de si mesmo junto aos outros, igualmente

\footnotetext{
${ }^{03}$ Segundo Fábio Konder Comparato, "No centro do período, entre 600 e 480 a.C., coexistiram, sem se comunicarem entre si, alguns dos maiores doutrinadores de todos os tempos: Zaratrustra na Pérsia, Buda na Índia, Lao-Tsé e Confúcio na China, Pitágoras na Grécia e o Dêutero-Isaías em Israel. Todos eles, cada um a seu modo, foram autores de visões do mundo, a partir das quais estabeleceu-se a grande linha divisória histórica: as explicações mitológicas anteriores são abandonadas, e o curso posterior da História passa a constituir um longo desdobramento das ideias e princípios expostos durante esse período". Ainda, acrescenta o mencionado autor que "Foi durante o período axial que se enunciaram os grandes princípios e se estabeleceram as diretrizes fundamentais de vida, em vigor até hoje." (COMPARATO, Fábio Konder. A afirmação histórica dos direitos humanos. 11. ed. São Paulo: Saraiva, 2017, p. 20-21).

${ }^{04}$ Ibid., p. 24.
} 
dotados do direito e do dever de dispor de si. $^{05}$

No entanto, o curso da história da humanidade demonstrou de modo clarividente que os direitos humanos não são direitos estáticos e incontestáveis por que decorreriam da própria natureza do homem, mas, ao revés, são fruto de um longo processo de lutas, violações, afirmações e mudanças sociais, culturais e tecnológicas. Nas palavras de Flávia Piovesan, "os direitos humanos refletem um construído axiológico, a partir de um espaço simbólico de luta e ação social”. ${ }^{6}$

$\mathrm{O}$ rol dos direitos humanos - ou dos direitos tidos como naturais e inalienáveis - nem sempre foi o mesmo, sofrendo diversas alterações e acréscimos no decorrer do tempo, a depender das necessidades e valores de uma determinada sociedade num dado contexto histórico, como bem observa Norberto Bobbio. ${ }^{07}$

O elenco dos direitos do homem se modificou, e continua a se modificar, com a mudança das condições históricas, ou seja, dos carecimentos e dos interesses, das classes no poder, dos meios disponíveis para a realização dos mesmos, das transformações técnicas, etc. [...] O que prova que não existem direitos fundamentais por natureza. O que parece fundamental numa época histórica e numa determinada civilização não é fundamental em outras épocas e em outras culturas. ${ }^{08}$

A historicidade axiológica ínsita aos direitos humanos pode ser observada pela constante necessidade de aperfeiçoamento e criação de novos documentos internacionais sobre a matéria, ${ }^{09}$ bem como pela classificação das gerações ou dimensões de direitos. Tais gerações, na realidade, refletem quais valores eram caros à sociedade num determinado tempo histórico. Assim, num primeiro momento os direitos civis e políticos (primeira geração) - também conhecidos como direitos ou liberdades negativas, por imporem restrições ao poder estatal - foram estimados como dignos de uma proteção especial, o que posteriormente foi estendido aos direitos econômicos, sociais e culturais (segunda geração) - com alguma resistência dos Estados liberais, visto que lhes impunham obrigações positivas - e finalmente aos direitos de solidariedade (terceira geração).

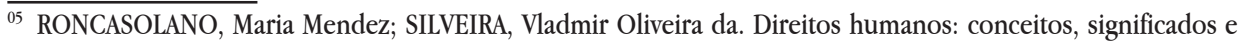
funções. São Paulo: Saraiva, 2010, passim.

${ }^{06}$ PIOVESAN, Flávia. Temas de direitos humanos. 10. ed. São Paulo: Saraiva, 2017, p. 213.

${ }^{07}$ BOBBIO, Norberto. A era dos direitos. Rio de Janeiro: Elsevier, 2004, p. 31-34.

${ }^{08}$ Ibid., p. 18.

${ }^{09}$ Ibid., p. 34.
} 
Há, ainda, aqueles que afirmem já existirem novas gerações de direitos, que englobariam "direitos como ao pluralismo político, o direito à paz universal, direitos ligados à área cibernética (como o direito fundamental à internet), além de todos os direitos ligados à área da genética (como a proteção ao patrimônio genético)", ${ }^{10}$ mas sobre os quais ainda não há consenso quanto ao seu conteúdo e tampouco quanto a sua classificação.

Tal processo histórico e axiológico que transforma os mais relevantes valores sociais em direitos humanos é intitulado dinamogenesis dos direitos humanos, assim ilustrado por Vladmir Oliveira da Silveira e Maria Mendez Rocasolano:

O elemento da historicidade é de fundamental importância na evolução dos direitos humanos, consoante as carências e interesses da sociedade, as transformações técnicas e as classes que estejam no poder - evidência desse caráter histórico são as "gerações" ou "dimensões" de direitos humanos. Tal perspectiva determina-lhes um caráter expansivo/ comunicativo, que afeta tanto a ideia como o conteúdo dos direitos humanos. Historicamente, por força deste caráter expansivo nascem novos direitos, consequência da dinâmica interna dos direitos preexistentes, num processo denominado dinamogenesis dos direitos humanos. ${ }^{11}$

Importa ressaltar, segundo os supracitados autores, que os direitos humanos em todas as suas dimensões gravitam em torno do conceito nuclear de dignidade da pessoa humana e que, apesar de tais direitos estarem em constante transformação, os novos direitos não substituem ou excluem os antigos direitos já consolidados. ${ }^{12}$

É nessa perspectiva histórica e axiológica que os Objetivos de Desenvolvimento Sustentável - que serão adiante analisados pormenorizadamente - devem ser compreendidos, ou seja, como parte do processo de evolução da significação e abrangência dos direitos humanos, no intuito de que estes passem a exprimir a realidade e os anseios do mundo atual.

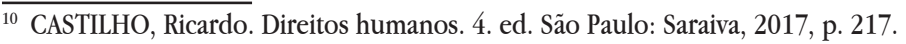

${ }^{11}$ RONCASOLANO; SILVEIRA, 2010, p. 231.

${ }^{12}$ Ibid., p. 200-201.
} 


\section{DIREITOS HUMANOS NA CONTEMPORANEIDADE}

\section{A fase contemporânea dos direitos humanos foi inaugurada com a Declaração} Universal dos Direitos Humanos de 1948. A enorme relevância da Declaração se dá na medida em que foi a primeira a conjugar, num mesmo documento internacional, direitos civis e políticos com direitos econômicos, sociais e culturais; além de ter sido a primeira a afirmar a universalidade dos direitos humanos como decorrência da dignidade humana, ${ }^{13}$ tendo sido aceita pela unanimidade ${ }^{14}$ dos Estados que compunham a sociedade internacional à época, com apenas oito abstenções ${ }^{15}$.

Embora a Declaração Universal não consista formalmente num tratado internacional, mas apenas numa resolução da Assembleia Geral das Nações Unidas, é consenso na doutrina que ela possui efetivamente força jurídica vinculante. A única divergência repousa no fundamento de tal vinculatividade. Para alguns, como Flávia Piovesan, tal característica decorre do fato de a Declaração ser "a interpretação autorizada da expressão 'direitos humanos', constante da Carta das Nações Unidas". ${ }^{16}$ Entretanto, para outros, como Fábio Konder Comparato, "[...] os direitos definidos na Declaração de 1948 correspondem, integralmente, ao que o costume e os princípios jurídicos internacionais reconhecem, hoje, como normas imperativas de direito internacional (jus cogens)", ${ }^{17}$ daí decorrendo a sua força vinculante.

Após a Declaração Universal foram aprovados diversos outros tratados

${ }_{13}$ PIOVESAN, Flávia. Direitos humanos e o direito constitucional internacional. 13. ed. São Paulo: Saraiva, 2012, p. 210.

${ }^{14}$ José Augusto Lindgren Alves adverte para o fato de que quando da adoção da Declaração Universal de 1948, a ONU era composta por apenas 56 Estados "ocidentais ou "ocidentalizados", de modo que a sua universalidade foi questionada e o documento rotulado como "produto do Ocidente". Ainda, Boaventura de Sousa Santos (2006, p. 433) ressalta que "[...] durante muitos anos, após a Segunda Guerra Mundial, os direitos humanos foram parte integrante da política da guerra-fria, e como tal foram considerados pelas forças políticas de esquerda. Duplos critérios na avaliação das violações dos direitos humanos, complacência para com ditadores amigos do Ocidente, defesa do sacrifício dos direitos humanos em nome dos objectivos do desenvolvimento - tudo isso tornou os direitos humanos suspeitos enquanto guião emancipatório" (ALVES, José Augusto Lindgren. A Declaração dos Direitos Humanos na pós-modernidade. Disponível em: < http://www.egov.ufsc. br/portal/sites/default/files/anexos/25499-25501-1-PB.pdf > . Acesso em: 02 set. 2018).

${ }^{15}$ Flávia Piovesan revela que "A Declaração Universal foi aprovada pela Resolução n. 217 A (III) da Assembleia Geral [da ONU], em 10 de dezembro de 1948, por 48 votos a zero e oito abstenções. Os oito Estados que se abstiveram foram: Bielo-rússia, Checoslováquia, Polônia, Arábia Saudita, Ucrânia, URSS, África do Sul e Iugoslávia. Observe-se que em Helsinki, em 1975, no Ato Final da Conferência sobre Segurança e Cooperação da Europa, os Estados comunistas da Europa aderiram expressamente à Declaração Universal." (PIOVESAN, 2012, p. 203).

16 PIOVESAN, 2012, p. 211.

${ }^{17}$ COMPARATO, 2017, p. 239. 
no âmbito da ONU sobre temas específicos dos direitos humanos, ${ }^{18}$ cabendo aqui uma especial referência à Convenção para a Prevenção e Repressão ao Crime de Genocídio, também de 1948; ao Pacto Internacional de Direitos Civis e Políticos e ao Pacto Internacional dos Direitos Econômicos, Sociais e Culturais, ambos de 1966, e seus respectivos protocolos facultativos; à Convenção Internacional sobre a Eliminação de Todas as Formas de Discriminação Racial, de 1965; à Convenção sobre a Eliminação de Todas as Formas de Discriminação Contra as Mulheres, de 1979; à Convenção Contra a Tortura e Outros Tratamentos ou Penas Cruéis, Desumanos ou Degradantes, de 1984; à Convenção sobre os Direitos das Crianças, de 1989; e à Convenção sobre os Direitos das Pessoas com Deficiência, de 2006. O conjunto desses e outros tratados compõe o marco normativo do Sistema Global de Direitos Humanos. ${ }^{19}$

Paralelamente ao sistema global, há também os sistemas regionais de proteção dos direitos humanos: o Interamericano, o Europeu e o Africano. Tais sistemas possuem seus respectivos arcabouços legais internacionais de proteção, sendo merecedora de especial destaque, pela sua aplicabilidade imediata em relação ao Brasil, a Convenção Americana de Direitos Humanos de 1969, criada no âmbito da Organização dos Estados Americanos (OEA).

Uma das questões mais frequentes nos debates sobre direitos humanos na contemporaneidade envolve a oposição entre universalismo e relativismo cultural. Sem ter a pretensão de esgotar o assunto, que é merecedor de amplo e aprofundado estudo, cumpre ressaltar que a adoção do universalismo em matéria de direitos humanos foi expressamente consignada na Convenção de Viena de 1993, que assim dispõe:

5. Todos os Direitos Humanos são universais, indivisíveis, interdependentes e interrelacionados. A comunidade internacional deve considerar os Direitos Humanos, globalmente, de forma justa e eqüitativa, no mesmo pé e com igual ênfase. Embora se deva ter sempre presente o significado das especificidades nacionais e regionais e os diversos antecedentes históricos, culturais e religiosos, compete aos Estados, independentemente dos seus sistemas políticos,

\footnotetext{
${ }_{18}$ AMARAL, Ana Paula Martins; CAMARGO, Caroline Leite de; MURTA, Eduardo Fretas. Educação em Direitos Humanos: princípios fundamentais. In: GUTIERREZ, José Paulo; URQUIZA, Antônio H. Aguilera (Org.). Direitos humanos e cidadania: desenvolvimento pela educação em direitos humanos. Campo Grande: Editora UFMS, 2013, p. 59.

19 PIOVESAN, op. cit., p. 226-227.
} 
econômicos e culturais, promover e proteger todos os Direitos Humanos e liberdades fundamentais. ${ }^{20}$

O universalismo funda-se na ideia de que os direitos humanos são universalmente aplicáveis porque decorrem diretamente da dignidade da pessoa humana. ${ }^{21}$ Entretanto, os adeptos do relativismo cultural tecem contundentes críticas ao universalismo, sob o argumento de que tal ideia na realidade reveste-se de um caráter imperialista, de imposição da cultura ocidental - mais precisamente, da cultura euro-atlântica - sobre o restante do globo, desconsiderando as particularidades e tradições das diversas culturas existentes. ${ }^{22}$ Portanto, consistiria num novo colonialismo.

Apesar de Boaventura de Sousa Santos afirmar ser necessária a superação da discussão acerca do universalismo versus relativismo para a transformação dos direitos humanos num projeto cosmopolita insurgente, ${ }^{23}$ equaciona bem o problema da abrangência e eficácia dos direitos humanos no mundo globalizado pós-moderno ao asseverar que:

Atravessado por concepções tão contraditórias e com violações ocorrendo a uma escala global, o campo dos direitos humanos tornou-se altamente controverso. E a controvérsia não cessa de se aprofundar à medida que o enfrentamento entre globalização hegemónica e a globalização contra-hegemónica vai revelando que, em muitos aspectos cruciais, as políticas de direitos humanos são políticas culturais. De tal forma que hoje, no início do XXI, podemos pensar que os direitos humanos como simbolizando o regresso do cultural e mesmo do religioso. Ora, falar de cultura e de religião é falar de diferença, de fronteiras, de particularismos. Como poderão os direitos humanos ser uma política simultaneamente cultural e global? ${ }^{24}$

\footnotetext{
${ }^{20}$ ONU MULHERES, Entidade das Nações Unidas para a Igualdade de Gênero e o Empoderamento das Mulheres. Declaração e Programa de Ação de Viena, 1993. Disponível em: < http://www.onumulheres.org.br/wp-content/ uploads/2013/03/declaracao_viena.pdf > . Acesso em: 02 set. 2018.

${ }^{21}$ PIOVESAN, 2012, p. 218.

${ }^{22}$ BENVENUTO, Jayme. Universalismo, relativismo e direitos humanos: uma revisita contingente. Lua Nova, São Paulo, n. 94, p. 117-142, abr. 2015. Disponível em: <http://www.scielo.br/scielo.php?script=sci arttext\&pid $=$ S0102-64452015000100005\&lng $=$ en\&nrm =iso > . Acesso em: 02 set. 2018.

${ }^{23}$ SANTOS, Boaventura de Sousa. A gramática do tempo: para uma nova cultura política. São Paulo: Cortez, 2006, p. 445.

${ }^{24}$ SANTOS, 2006, p. 437.
} 
Na visão do supracitado jurista e sociólogo português, para que os direitos humanos superem o modelo hegemônico liberal e se libertem da dicotomia entre universalismo e relativismo cultural, alcançando verdadeiramente um caráter emancipatório na contemporaneidade, devem adquirir um paradigma intercultural (ou multicultural) que abarca as diversas culturas existentes no globo para formar uma nova concepção de dignidade humana. ${ }^{25}$

Em sentido semelhante, porém distinto, Joaquin Herrera Flores afirma que tanto o universalismo quanto o relativismo (por ele chamado de 'multiculturalismo') são "produtos de visões reducionistas da realidade". A partir da crítica a tais concepções de direitos humanos, o jusfilósofo espanhol trata da necessidade de se enxergar esses direitos a partir da periferia (em contraposição a uma visão central), com a consideração positiva do contexto e a participação de múltiplas vozes, de modo que o universalismo passe a ser entendido como ponto de chegada (e não de partida) em que efetivamente são levadas em conta as inúmeras diferenças culturais, ao que o autor denomina de racionalidade de resistência pela prática intercultural. ${ }^{26}$

Não obstante as diversas discussões teóricas na seara dos direitos humanos - cujo debate abrange desde a fundamentação, até a validade de tais direitos -, uma das questões que mais desperta preocupação na contemporaneidade é relativa à sua eficácia. Como bem observa Herrera Flores, "Falar de direitos humanos, no mundo contemporâneo, supõe enfrentar-se desafios completamente diferentes dos que enfrentaram os redatores da Declaração Universal de 1948", tendo em conta que "Vivemos, pois, na época da exclusão generalizada". ${ }^{27}$

Com efeito, as mais recentes estimativas sobre pobreza, fome, educação, desigualdades, meio ambiente e desenvolvimento no mundo são ainda estarrecedoras, como veremos de modo pormenorizado adiante. Justamente em razão dessa realidade perturbadora acerca da concretude dos direitos humanos, há algum tempo Norberto Bobbio alertava que:

Com efeito, o problema que temos diante de nós não é filosófico, mas jurídico e, num sentido mais amplo, político. Não se trata de saber quais e quantos são esses direitos, qual é sua natureza e seu fundamento, se são direitos naturais ou

\footnotetext{
${ }^{25}$ Ibid., p. 470.

${ }^{26}$ FLORES, Joaquin Herrera. Direitos humanos, interculturalidade e racionalidade de resistência. Seqüência: Estudos Jurídicos e Políticos, Florianópolis, p. 9-30, jan. 2002. Disponível em: <https://periodicos.ufsc.br/ index.php/sequencia/article/view/15330 > . Acesso em: 02 set. 2018.

${ }^{27}$ Id.
} 
históricos, absolutos ou relativos, mas sim qual é o modo mais seguro para garanti-los, para impedir que, apesar das solenes declarações, eles sejam continuamente violados. ${ }^{28}$

A humanidade se vê, pois, diante da difícil tarefa de tornar real, possível e concreto o extenso rol de direitos humanos assegurados por meio dos tratados e costumes internacionais, sob pena de ter a aspiração transformadora dos direitos humanos convertida em mera enunciação de belos preceitos sem correspondência com a realidade. É nesse contexto de busca por ações transformadoras que estão inseridos os Objetivos de Desenvolvimento Sustentável da ONU.

\section{OBJETIVOS DE DESENVOLVIMENTO SUSTENTÁVEL}

Os Objetivos de Desenvolvimento Sustentável integram o documento intitulado "Transformando Nosso Mundo: a Agenda 2030 para o Desenvolvimento Sustentável". ${ }^{29}$ Tal documento, também conhecido simplesmente como Agenda 2030, foi acordado entre os 193 Estados-membros da ONU, durante a Cúpula das Nações Unidas para o Desenvolvimento Sustentável ocorrida em setembro de 2015, na sede da ONU em Nova Iorque. ${ }^{30}$

Segundo definição do Programa das Nações Unidas para o Desenvolvimento (PNUD), o desenvolvimento sustentável é aquele que "procura satisfazer as necessidades da geração atual, sem comprometer a capacidade das futuras gerações de satisfazerem as suas próprias necessidades". ${ }^{31}$

As primeiras discussões sobre desenvolvimento sustentável se deram na Conferência das Nações Unidas sobre Meio Ambiente e Desenvolvimento, realizada no Rio de Janeiro em 1992 (Rio 92). Após, as discussões se seguiram na Cúpula Mundial sobre Desenvolvimento Sustentável, ocorrida em Johanesburgo em 2002

\footnotetext{
$\overline{{ }^{28} \text { BOBBIO, 2004, p. } 25 .}$

${ }^{29}$ ONU, Organização das Nações Unidas. Transformando Nosso Mundo: A Agenda 2030 para o Desenvolvimento Sustentável, 2015. Disponível em: < https://nacoesunidas.org/wp-content/uploads/2015/10/agenda2030-pt-br. pdf > . Acesso em: 02 set. 2018.

30 ONU, Organização das Nações Unidas. Cúpula das Nações Unidas sobre o Desenvolvimento Sustentável: Transformar nosso mundo para as Pessoas e o Planeta, 2017a. Disponível em: < https://nacoesunidas.org/ pos2015/cupula/> . Acesso em: 02 set. 2018.

${ }^{31}$ PNUD, Programa das Nações Unidas para o Desenvolvimento. As perguntas mais frequentes sobre os Objetivos de Desenvolvimento Sustentável (ODS), 29 jun. 2016. Disponível em: <http://www.br.undp.org/content/ brazil/pt/home/library/ods/cartilha-de-perguntas-e-respostas-dos-ods.html> . Acesso em: 15 nov. 2017.
} 
(Rio +10); na Cúpula das Nações Unidas sobre os Objetivos de Desenvolvimento do Milênio, ocorrida em 2010 em Nova Iorque; e na Conferência das Nações Unidas sobre Desenvolvimento Sustentável, realizada no Rio de Janeiro em 2012 $($ Rio +20$) .{ }^{32}$ Foi na Rio +20 que se convencionou a necessidade de estabelecimento de novos objetivos e metas para sucederem os Objetivos de Desenvolvimento do Milênio (ODM).

Os ODM consistem em 8 objetivos $^{33}, 21$ metas e 60 indicadores que integram a Declaração do Milênio, adotada pelos Estados-membros da ONU na Cúpula do Milênio, ocorrida no ano 2000 na sede da ONU em Nova Iorque. ${ }^{34}$ Os ODM refletiram um compromisso real adotado pela sociedade internacional, para uma efetiva transformação até 2015 dos maiores desafios que o mundo enfrentava àquela época. Acerca do escopo dos debates na Conferência do Milênio, que levaram à criação dos ODM, Denise Schmitt Siqueira Garcia e Heloise Siqueira Garcia relatam que:

Outrossim, [os países envolvidos] focaram esforços e discussões acerca de temas que convergiam as preocupações mundiais, como paz, segurança, desarmamento, desenvolvimento, erradicação da pobreza, proteção do ambiente comum, direitos humanos, democracia, boa governança, proteção dos grupos vulneráveis, responder às necessidades especiais da África e reforçar as Nações Unidas. ${ }^{35}$

Decorrido o prazo para cumprimento dos ODM em 2015, verificou-se que vários resultados positivos foram alcançados, inclusive com o atingimento de algumas metas, dentre as quais destaca-se a redução pela metade do número de pessoas que viviam na extrema pobreza, a ampliação da participação política das mulheres, a diminuição de aproximadamente $40 \%$ do número de infecções por HIV/Aids e a

\footnotetext{
32 ONU, 2017a.

33 Os oito objetivos que compõem os ODM são: 1) acabar com a fome e a miséria; 2) educação básica de qualidade para todos; 3) igualdade entre os sexos e valorização da mulher; 4) reduzir a mortalidade infantil; 5) melhorar a saúde das gestantes; 6) combater a AIDS, a malária e outras doenças; 7) qualidade de vida e respeito ao meio ambiente; e 8) estabelecer parcerias para o desenvolvimento (PNUD, 2016).

${ }^{4}$ UNICEF, Fundo das Nações Unidas para a Infância. Objetivos de Desenvolvimento do Milênio. Disponível em: < https://www.unicef.org/brazil/pt/resources_9540.htm>. Acesso em: 02 set. 2018.

35 GARCIA, Denise Schmitt Siqueira; GARCIA, Heloise Siqueira. Objetivos de Desenvolvimento do Milênio e as novas perspectivas do desenvolvimento sustentável pela Organização das Nações Unidas. Revista da Faculdade de Direito da UFRGS, Porto Alegre, n. 35, vol. esp., p. 192-206, dez. 2016. Disponível em: < http://seer.ufrgs. br/index.php/revfacdir/article/view/69455/40499>. Acesso em: 02 set. 2017.
} 
diminuição de óbitos por malária e tuberculose ${ }^{36}$ Ainda de acordo com o PNUD, "Os ODM produziram o mais bem-sucedido movimento de redução da pobreza da história e serviram como ponto de partida para a nova agenda de desenvolvimento sustentável" ${ }^{37}$.

No entanto, após 2015 era preciso dar continuidade às ações iniciadas com os ODM, tanto pelo fato de que estes deixaram algumas lacunas ${ }^{38}$, como em razão de que com eles demonstrou-se que é possível o atingimento de metas concretas. ${ }^{39}$ Sobrevieram, então, os ODS que entraram em vigência em 01 de janeiro de 2016, e cujo prazo final para cumprimento é 31 de dezembro de $2030 .{ }^{40}$

Algumas das principais diferenças entre os ODM e os ODS residem na amplitude dos temas abordados e na abrangência de aplicação. Isso porque os ODS tratam de um maior número de questões e com maior profundidade em relação aos ODM, como, por exemplo, da segurança alimentar, sustentabilidade na agricultura, disponibilidade e gestão da água e saneamento, acesso à energia, emprego pleno e produtivo, construção de infraestrutura e promoção da industrialização, segurança e sustentabilidade de cidades e assentamentos humanos, consumo sustentável, mudanças climáticas, conservação dos oceanos, gestão das florestas e combate à desertificação e acesso à justiça e instituições eficazes. Com relação à aplicabilidade, enquanto os ODM estavam focados nos países pobres, os ODS possuem uma ação mais ampla com perspectiva de alcance global, portanto são universalmente aplicáveis. Contudo, é importante observar que a Agenda 2030 em que estão inseridos os ODS não foi formalizada como tratado, desse modo não possui efeito vinculante, ${ }^{41}$ haja vista ser norma de soft law.

Os ODS são fruto de mais de dois anos de negociações entre Estados. O seu processo de elaboração foi coordenado por um Grupo de Trabalho Aberto

\footnotetext{
${ }_{36}$ PNUD, Programa das Nações Unidas para o Desenvolvimento. PNUD explica transição dos Objetivos do Milênio aos Objetivos de Desenvolvimento Sustentável, 08 dez. 2015. Disponível em: $<$ https://nacoesunidas. org/pnud-explica-transicao-dos-objetivos-do-milenio-aos-objetivos-de-desenvolvimento-sustentavel/> . Acesso em: 22 nov. 2017.

${ }^{37}$ PNUD, 2016.

${ }^{38}$ Segundo Denise Schmitt Siqueira Garcia e Heloise Siqueira Garcia, algumas das principais lacunas deixadas pelos ODM foram: "[...] a persistência da desigualdade de gêneros; grandes desnivelamentos e lacunas sociais entre os mais pobres e mais ricos, assim como entre as áreas rurais e urbanas; as alterações climáticas e a degradação ambiental prejudicaram o progresso alcançado e a população pobre foi a que mais sofreu; os conflitos continuam sendo o maior problema no desenvolvimento humano; milhões de pessoas consideradas pobres ainda vivem na extrema pobreza e com fome e sem acesso a serviços básicos" (GARCIA; GARCIA, p. 200).

${ }^{39}$ CASTILHO, 2017, p. 391.

${ }^{40}$ PNUD, 2016.

${ }^{41}$ Id.
} 
da Assembleia Geral da ONU e contou com ampla participação da sociedade civil, por meio da pesquisa "Meu Mundo", na qual participaram mais de 7 milhões de pessoas. $^{42}$

Ainda, os ODS englobam as três dimensões fundamentais do desenvolvimento sustentável, quais sejam: ambiental, social e econômica, sendo que a sustentabilidade reside exatamente no ponto de convergência entre estas três dimensões. Para mais além, os ODS são divididos em cinco elementos subjacentes: pessoas, planeta, parcerias, paz e prosperidade, conhecidos como os cinco P's dos Objetivos de Desenvolvimento Sustentável. Mas, afinal, quais são e no que consistem os ODS?

Os ODS são compostos por 17 objetivos e 169 metas que visam atingir o desenvolvimento sustentável do planeta até $2030{ }^{43}$

Para cada um dos objetivos há diversas metas, algumas com conteúdo mais abrangente e genérico, como é o caso da meta 5.1, pela qual pretende-se "Acabar com todas as formas de discriminação contra todas as mulheres e meninas em toda parte"; ${ }^{44}$ e outras com um objeto bastante delimitado e específico, a exemplo da meta 3.1, que consiste em "Até 2030, reduzir a taxa de mortalidade materna global para menos de 70 mortes por 100.000 nascidos vivos". ${ }^{45}$

O acompanhamento e avaliação quanto à implementação dos ODS se dá de modo voluntário e com a liderança dos Estados-membros da ONU, por meio de revisões periódicas acerca dos avanços obtidos nos níveis subnacional, nacional,

42 Id.

43 Objetivo 1: Acabar com a pobreza em todas as suas formas, em todos os lugares; Objetivo 2. Acabar com a fome, alcançar a segurança alimentar e melhoria da nutrição e promover a agricultura sustentável; Objetivo 3. Assegurar uma vida saudável e promover o bem-estar para todos, em todas as idades; Objetivo 4. Assegurar a educação inclusiva e equitativa e de qualidade, e promover oportunidades de aprendizagem ao longo da vida para todos; Objetivo 5 . Alcançar a igualdade de gênero e empoderar todas as mulheres e meninas; Objetivo 6. Assegurar a disponibilidade e gestão sustentável da água e saneamento para todos; Objetivo 7. Assegurar o acesso confiável, sustentável, moderno e a preço acessível à energia para todos; Objetivo 8. Promover o crescimento econômico sustentado, inclusivo e sustentável, emprego pleno e produtivo e trabalho decente para todos; Objetivo 9. Construir infraestruturas resilientes, promover a industrialização inclusiva e sustentável e fomentar a inovação; Objetivo 10. Reduzir a desigualdade dentro dos países e entre eles; Objetivo 11. Tornar as cidades e os assentamentos humanos inclusivos, seguros, resilientes e sustentáveis; Objetivo 12. Assegurar padrões de produção e de consumo sustentáveis; Objetivo 13. Tomar medidas urgentes para combater a mudança do clima e seus impactos; Objetivo 14. Conservação e uso sustentável dos oceanos, dos mares e dos recursos marinhos para o desenvolvimento sustentável; Objetivo 15. Proteger, recuperar e promover o uso sustentável dos ecossistemas terrestres, gerir de forma sustentável as florestas, combater a desertificação, deter e reverter a degradação da terra e deter a perda de biodiversidade; Objetivo 16. Promover sociedades pacíficas e inclusivas para o desenvolvimento sustentável, proporcionar o acesso à justiça para todos e construir instituições eficazes, responsáveis e inclusivas em todos os níveis; Objetivo 17. Fortalecer os meios de implementação e revitalizar a parceria global para o desenvolvimento sustentável (ONU, 2015).

${ }^{44}$ ONU, 2015.

${ }^{45}$ Id. 
regional e global e de revisão geral nas reuniões do Fórum Político de Alto Nível sobre Desenvolvimento Sustentável, com a formulação anual de relatório pelo Secretário-Geral da ONU. São utilizados em tal acompanhamento 230 indicadores $^{46}$ desenvolvidos pelo Grupo Interagencial de Peritos sobre os indicadores dos Objetivos de Desenvolvimento Sustentável (GIPI-ODS). ${ }^{47}$

O PNUD ressalta como de fundamental importância para o sucesso dos ODS o processo de localização destes em âmbito subnacional. ${ }^{48}$ No Brasil, tal processo consiste em adaptar os ODS para a realidade local de Estados e Municípios, de modo a eleger políticas públicas e encontrar soluções para os problemas locais conforme o que apregoa a Agenda 2030. Segundo informações da ONU, no nosso país os governos de São Paulo, Minas Gerais, Distrito Federal, Pará, Piauí, Ceará, Paraíba, Bahia e Paraná já inseriram os ODS em suas políticas públicas ou estão em vias de implementação. ${ }^{49}$

Ainda no Brasil, o Grupo de Trabalho da Sociedade Civil para a Agenda 2030, composto por participantes de diferentes setores, tem monitorado a implementação dos ODS. Em junho de 2017 o Grupo divulgou o "Relatório Luz da Agenda 2030 de Desenvolvimento Sustentável", no qual foram analisados os estágios de cumprimento dos ODS 1, 2, 3, 5, 9, 14 e 17, e se concluiu que a tensão social na qual o país vivia, em decorrência das crises política e econômica, prejudicava o atingimento dos objetivos principalmente em razão de discursos políticos violadores de direitos humanos que têm ganhado força. Os ODS e metas mais prejudicados nessa conjuntura seriam os relacionados à erradicação da pobreza, fome, agricultura sustentável e igualdade de gênero..$^{50}$

\footnotetext{
${ }_{46}$ De acordo com informações do PNUD, dos 230 indicadores que existem atualmente acerca dos ODS há consenso sobre 150 deles (verdes), e outros 80 (cinzas) ainda estão em debates (PNUD, 2016).

47 Id.

${ }^{48}$ PNUD, 2016.

${ }^{49}$ ONU, Organização das Nações Unidas. Objetivos de Desenvolvimento Sustentável da ONU completam 2 anos, 25 set. 2017c. Disponível em: < https://nacoesunidas.org/objetivos-de-desenvolvimento-sustentavel-da-onucompletam-2-anos/> . Acesso em: 02 set. 2018.

${ }^{50}$ GRUPO DE TRABALHO DA SOCIEDADE CIVIL PARA AGENDA 2030. Relatório Luz da Agenda 2030 para desenvolvimento sustentável, 2017. Disponível em: <https://brasilnaagenda2030.files.wordpress. com/2017/07/relatorio-luz-gtsc-brasil-hlpf2017.pdf> . Acesso em: 02 set. 2018.
} 


\section{OS OBJETIVOS DE DESENVOLVIMENTO SUSTENTÁVEL COMO REFLEXO DOS DIREITOS HUMANOS NA CONTEMPORANEIDADE}

\section{Os Objetivos de Desenvolvimento Sustentável são reflexos do atual estágio} dos direitos humanos globalmente considerados, seja porque consistem numa reafirmação do rol de tais direitos, seja porque trazem metas concretas com a finalidade de alcançá-los e protegê-los.

Com efeito, alguns objetivos e metas consistem verdadeiramente em reiterações de direitos civis e políticos e direitos econômicos, sociais e culturais já consagrados (direitos de primeira e segunda geração). Outros, dizem respeito às formas de implementação de tais direitos, notadamente os sociais, dispondo sobre meios concretos para se alcançar o desenvolvimento sustentável, inclusive no que toca a questões financeiras, de disponibilização de crédito e de crescimento econômico dos países, consistindo assim em preceitos relativos aos direitos de terceira geração. Nesse sentido, a título exemplificativo, merecem destaque as metas 2.3, 7.3, 8.1, 9.1, 9.2, 10.1, 12.3 e $17.2^{51}$ dos ODS.

A existência de objetivos e metas que apontam para possíveis soluções com relação a formas de concretização de direitos humanos revela a preocupação da comunidade internacional - e notadamente da $\mathrm{ONU}$ - com a proteção e efetivação destes direitos, e nos remete ao pensamento de Bobbio sobre o real desafio dos direitos humanos na pós-modernidade ${ }^{52}$.

\footnotetext{
${ }^{51}$ Meta 2.3: "Até 2030, dobrar a produtividade agrícola e a renda dos pequenos produtores de alimentos, particularmente das mulheres, povos indígenas, agricultores familiares, pastores e pescadores, inclusive por meio de acesso seguro e igual à terra, outros recursos produtivos e insumos, conhecimento, serviços financeiros, mercados e oportunidades de agregação de valor e de emprego não agrícola". Meta 7.3: "Até 2030, dobrar a taxa global de melhoria da eficiência energética". Meta 8.1: "Sustentar o crescimento econômico per capita de acordo com as circunstâncias nacionais e, em particular, um crescimento anual de pelo menos 7\% do produto interno bruto [PIB] nos países menos desenvolvidos". Meta 9.1: "Desenvolver infraestrutura de qualidade, confiável, sustentável e resiliente, incluindo infraestrutura regional e transfronteiriça, para apoiar o desenvolvimento econômico e bem-estar humano, com foco no acesso equitativo e a preços acessíveis para todos". Meta 9.2: "Promover a industrialização inclusiva e sustentável e, até 2030, aumentar significativamente a participação da indústria no setor de emprego e no PIB, de acordo com as circunstâncias nacionais, e dobrar sua participação nos países menos desenvolvidos". Meta 10.1: "Até 2030, progressivamente alcançar e sustentar o crescimento da renda dos $40 \%$ da população mais pobre a uma taxa maior que a média nacional". Meta 12.3: "Até 2030, reduzir pela metade o desperdício de alimentos per capita mundial, nos níveis de varejo e do consumidor, e reduzir as perdas de alimentos ao longo das cadeias de produção e abastecimento, incluindo as perdas pós-colheita". Meta 17.2: "Países desenvolvidos implementarem plenamente os seus compromissos em matéria de assistência oficial ao desenvolvimento [AOD], inclusive fornecer $0,7 \%$ da renda nacional bruta $[\mathrm{RNB}]$ em AOD aos países em desenvolvimento, dos quais $0,15 \%$ a $0,20 \%$ para os países menos desenvolvidos; provedores de AOD são encorajados a considerar a definir uma meta para fornecer pelo menos 0,20\% da renda nacional bruta em AOD para os países menos desenvolvidos". (ONU, 2015).

${ }^{52}$ Nesse mesmo sentido, Flávia Piovesan afirma que: "Uma das maiores fragilidades do sistema internacional de direitos humanos atém-se às dificuldades de implementação de direitos - o chamado 'implementation gap'" (PIOVESAN, 2017, p. 220).
} 
A efetivação de uma maior proteção dos direitos do homem está ligada ao desenvolvimento global da civilização humana. É um problema que não pode ser isolado, sob pena, não digo de não resolvê-lo, mas de sequer compreendê-lo em sua real dimensão. Quem o isola já o perdeu. Não se pode pôr o problema dos direitos do homem abstraindo-o dos dois grandes problemas de nosso tempo, que são os problemas da guerra e da miséria, do absurdo contraste entre o excesso de potência que criou as condições para uma guerra exterminadora e o excesso de impotência que condena grandes massas humanas à fome..$^{53}$

Não se pode perder de vista o fato de que a pobreza é componente inicial de muitas das violações aos direitos humanos, além de consistir em si mesma numa violação do direito humano ao desenvolvimento, ${ }^{54}$ entendido conforme a Declaração sobre o Direito ao Desenvolvimento de 1986.

Dados oficiais da ONU apontam que mesmo após os esforços dos países para a erradicação da pobreza por meio dos ODM - que como vimos, efetivamente surtiram resultados -, ainda existem no mundo 836 milhões de pessoas vivendo na extrema pobreza; 795 milhões de pessoas ainda são subnutridas; a mortalidade infantil ainda é de 6 milhões de crianças por ano; 57 milhões de crianças seguem sem frequentar a escola; 35 milhões de pessoas continuam vivendo com o vírus HIV; 2,5 bilhões de pessoas ainda não têm acesso a saneamento básico e mais de 1 bilhão de pessoas não tem condições de acessar água potável; 1,3 bilhão de pessoas continuam sem usufruir de energia elétrica; 828 milhões de pessoas moram em favelas; e mais de 4 bilhões de pessoas ainda não possuem acesso à internet. Mas a pobreza, suas causas e consequências podem ser visualizadas não só por dados relativos aos indivíduos, mas também pelos dados relativos às cidades e meio ambiente, a exemplos dos 1,3 bilhão de toneladas de comida desperdiçada diariamente e de que $52 \%$ da terra utilizada para agricultura está afetada moderada ou severamente pela degradação do solo. ${ }^{55}$

A pobreza ainda é, pois, uma lastimável realidade da humanidade.

\footnotetext{
53 BOBBIO, 2004, p. 44.

${ }^{54}$ COSTA, Fernanda Doz. Pobreza e direitos humanos: da mera retórica às obrigações jurídicas, um estudo crítico sobre diferentes modelos conceituais. Sur: Revista Internacional de Direitos Humanos, São Paulo, v. 5, n. 9, p. 88-119, dez. 2008. Disponível em: <http://www.scielo.br/scielo.php?pid=S1806$64452008000200006 \&$ script $=$ sci_abstract\&tlng $=$ pt $>$. Acesso em: 02 set. 2018.

55 ONU, Organização das Nações Unidas. Principais fatos, 2017d. Disponível em: < https://nacoesunidas.org/ pos2015/principais-fatos/>. Acesso em: 02 set. 2018.
} 
Atualmente ela é compreendida não apenas do ponto de vista econômico, como a falta de recursos, mas também a partir de enfoques sociais e culturais, "tornando-se um problema político, que afeta diretamente o desenvolvimento humano e, portanto a satisfação dos direitos humanos", como bem observa Elizabeth Salmón G. ${ }^{56}$

Contudo, evidentemente não se pode desconsiderar o fato de que a realização de alguns direitos humanos requer a disponibilização de recursos financeiros, o que torna patente a disparidade de condições entre os países pobres e os países ricos para o atingimento dos objetivos e metas da Agenda 2030. Por tal razão, é de fundamental importância que tantos os Estados pobres quanto os seus cidadãos tenham acesso a recursos financeiros de modo facilitado e sejam redefinidos alguns pontos relativos à dívida pública para não prejudicar a concretização dos ODS. Nessa perspectiva, Flávia Piovesan aduz que:

O Banco Mundial e o Fundo Monetário Internacional têm operado com diligência para reduzir o impacto da dívida e têm introduzido programas inovadores. Todavia, a perspectiva dos direitos humanos demanda que, em nenhuma circunstância, seja reduzida a receita de Estados a ponto de propiciar a violação de direitos, como o direito à alimentação, à saúde, à educação, à previdência social. Isto é, há que assegurar que ao menos um orçamento mínimo e básico seja mantido para a salvaguarda desses direitos. ${ }^{57}$

Não se poderão considerar atingidos os objetivos dos direitos humanos enquanto houver tamanha discrepância na realidade entre países ricos e pobres, que de modo geral revela-se na discrepância entre o eixo norte-sul do globo. É exatamente por essa razão que o ODS 17 trata de formas de parcerias para se alcançar o desenvolvimento sustentável equânime, ressaltando a importância da cooperação norte-sul e sul-sul e a prioridade da Agenda do Sul nas relações internacionais, além do princípio das obrigações comuns, porém diferenciadas.

Para a concretização dos direitos humanos na contemporaneidade é fundamental que se guarde coerência entre o que é anunciado nos instrumentos internacionais de proteção e aquilo que é efetivamente praticado pelos Estados,

\footnotetext{
${ }^{56}$ SALMÓN G., Elizabeth. O longo caminho da luta contra a pobreza e seu alentador encontro com os direitos humanos. Sur: Revista Internacional de Direitos Humanos, São Paulo, v. 4, n. 7, p. 152-167, 2007. Disponível em: $\quad<$ http://www.scielo.br/scielo.php?pid=S1806-64452007000200007\&script $=$ sci_abstract\&tlng $=$ pt $>$. Acesso em: 02 set. 2018.

${ }^{57}$ PIOVESAN, 2017, p. 225.
} 
Organizações Internacionais, Empresas Privadas e Sociedade Civil. Trata-se de conciliar a utopia própria de tais direitos com uma real e efetiva mudança no mundo em que vivemos. Nas palavras de Boaventura de Souza Santos:

Hoje começa a predominar um pensamento de emancipação concreta, um pensamento contextual que não recusa o carácter utópico dos direitos humanos mas exige que a sua utopia, por mais radical, se traduza num quotidiano diferente, no mapa de um novo modo de vida mais autêntico. [...] Não se desconhece que as declarações dos direitos humanos têm eficácia simbólica em si mesmas mas exige-se que essa eficácia não se obtenha à custa da ocultação da discrepância entre tais declarações e a vida prática dos cidadãos, exige-se em suma que os direitos humanos sejam efectivamente aplicados. ${ }^{58}$

Em última instância é disso que tratam os ODS e a Agenda 2030 como um todo. Ou seja, tratam de um plano de ação baseado nos direitos humanos já consagrados internacionalmente, abarcando todas as gerações de direitos, com o intuito de transformação da realidade a partir de medidas práticas, reais e efetivas, com prazos tangíveis, priorizando aqueles que mais necessitam de atenção, sejam estes indivíduos ou Estados.

\section{CONCLUSÃO}

Os direitos humanos estão em constante processo de transformação e agregação de valores, decorrente da historicidade que lhes é própria e lhes dá fundamento. No processo axiológico pelo qual novos valores da sociedade são elevados à categoria de direitos humanos, conforme o contexto social e cultural em que se vive, são criadas novas gerações ou dimensões de direitos, ao que se denomina dinamogenesis dos direitos humanos.

A concepção contemporânea de direitos humanos teve início com a Declaração Universal dos Direitos Humanos de 1948. Desde então, surgiram inúmeros outros documentos internacionais destinados à sua proteção e muito se debateu acerca da sua fundamentação e aplicabilidade, merecendo especial relevo o embate entre as doutrinas universalista e relativista dos direitos humanos. 
No entanto, a principal preocupação com os direitos humanos no mundo contemporâneo não guarda tanta relação com o aspecto teórico, mas prático. Tratase de encontrar meios efetivos para a promoção e proteção desses direitos, que continuam a ser alvo de constantes violações.

É nesse contexto de reafirmação e busca por soluções que possibilitem a efetiva implementação dos direitos humanos, que surgem os ODS no âmbito da ONU. Consistentes em 17 objetivos e 169 metas para o mundo alcançar o desenvolvimento sustentável até 2030, os ODS abarcam direitos de primeira, segunda e terceira geração e trazem medidas práticas, técnicas, reais e tangíveis a serem adotadas pelos Estados, Organizações Internacionais, Empresas Privadas e Sociedade Civil.

Os ODS são fruto do legado deixado pelos ODM, tanto em relação a seus méritos como em relação a suas lacunas. Assim, de uma maneira muito mais abrangente, os ODS têm o propósito de dar seguimento às ações para promoção do desenvolvimento sustentável, em suas dimensões econômica, social e ambiental.

Conclui-se, portanto, que a partir dos ODS pode-se ter uma nova compreensão dos direitos humanos na contemporaneidade, seja porque estes englobam os mais diversos direitos humanos consagrados internacionalmente, reafirmando-os com a aprovação da Agenda 2030 pelos 193 Estados-membros da ONU em 2015; seja em razão de refletirem a preocupação da comunidade internacional para com a implementação efetiva de tais direitos, ao proporem objetivos e metas reais, com prazo para cumprimento, assumindo, assim, o compromisso de transformar o mundo por intermédio do desenvolvimento sustentável e eliminar a pobreza e tantas outras mazelas que nos assombram até hoje.

\section{REFERÊNCIAS}

ALVES, José Augusto Lindgren. A Declaração dos Direitos Humanos na pósmodernidade. Disponível em: < http://www.egov.ufsc.br/portal/sites/default/files/ anexos/25499-25501-1-PB.pdf> . Acesso em: 14 nov. 2017.

AMARAL, Ana Paula Martins; CAMARGO, Caroline Leite de; MURTA, Eduardo Fretas. Educação em Direitos Humanos: princípios fundamentais. In: GUTIERREZ, José Paulo; URQUIZA, Antônio H. Aguilera (Org.). Direitos humanos e cidadania: desenvolvimento pela educação em direitos humanos. Campo Grande: Editora 
UFMS, 2013. pp. 41-64.

ARISTÓTELES. Ética a Nicômaco. Tradução de Leonel Vallandro e Gerd Bornheim da versão inglesa de W. D. Ross. São Paulo: Martin Claret, 2015.

BENVENUTO, Jayme. Universalismo, relativismo e direitos humanos: uma revisita contingente. Lua Nova, São Paulo, n. 94, p. 117-142, abr. 2015. Disponívelem: < http:// www.scielo.br/scielo.php?script $=$ sci_arttext $\&$ pid $=\$ 0102-64452015000100005 \& \ln$ $\mathrm{g}=\mathrm{en} \& \mathrm{nrm}=$ iso $>$. Acesso em: 15 nov. 2017.

BOBBIO, Norberto. A era dos direitos. Rio de Janeiro: Elsevier, 2004.

CASTILHO, Ricardo. Direitos humanos. 4. ed. São Paulo: Saraiva, 2017.

COMPARATO, Fábio Konder. A afirmação histórica dos direitos humanos. 11. ed. São Paulo: Saraiva, 2017.

COSTA, Fernanda Doz. Pobreza e direitos humanos: da mera retórica às obrigações jurídicas, um estudo crítico sobre diferentes modelos conceituais. Sur: Revista Internacional de Direitos Humanos, São Paulo, v. 5, n. 9, p. 88119, dez. 2008. Disponível em: <http://www.scielo.br/scielo.php?pid=S1806$64452008000200006 \&$ script $=$ sci_abstract\&tlng =pt $>$. Acesso em: 21 nov. 2017.

FLORES, Joaquin Herrera. Direitos humanos, interculturalidade e racionalidade de resistência. Seqüência: Estudos Jurídicos e Políticos, Florianópolis, p. 9-30, jan. 2002. Disponível em: < https://periodicos.ufsc.br/index.php/sequencia/article/ view/15330 > . Acesso em: 15 nov. 2017.

GARCIA, Denise Schmitt Siqueira; GARCIA, Heloise Siqueira. Objetivos de Desenvolvimento do Milênio e as novas perspectivas do desenvolvimento sustentável pela Organização das Nações Unidas. Revista da Faculdade de Direito da UFRGS, Porto Alegre, n. 35, vol. esp., p. 192-206, dez. 2016. Disponível em: < http://seer. ufrgs.br/index.php/revfacdir/article/view/69455/40499 > . Acesso em: 14 nov. 2017.

GRUPO DE TRABALHO DA SOCIEDADE CIVIL PARA AGENDA 2030. Relatório Luz da Agenda 2030 para desenvolvimento sustentável, 2017. Disponível em: $<$ https://brasilnaagenda2030.files.wordpress.com/2017/07/relatorio-luz-gtsc-brasilhlpf2017.pdf> . Acesso em: 23 nov. 2017. 
PIOVESAN, Flávia. Direitos humanos e o direito constitucional internacional. 13. ed. São Paulo: Saraiva, 2012.

PIOVESAN, Flávia. Temas de direitos humanos. 10. ed. São Paulo: Saraiva, 2017.

PROGRAMA DAS NAÇÕES UNIDAS PARA O DESENVOLVIMENTO - PNUD. As perguntas mais frequentes sobre os Objetivos de Desenvolvimento Sustentável (ODS), 29 jun. 2016. Disponível em: < http://www.br.undp.org/content/brazil/pt/ home/post-2015/materiais/perguntas-e-respostas.html > . Acesso em: 15 nov. 2017.

PROGRAMA DAS NAÇÕES UNIDAS PARA O DESENVOLVIMENTO - PNUD. Os Objetivos de Desenvolvimento Sustentável: dos ODM aos ODS, 2017. Disponível em: <http:/www.br.undp.org/content/brazil/pt/home/post-2015.html>. Acesso em: 22 nov. 2017.

PROGRAMA DAS NAÇÕES UNIDAS PARA O DESENVOLVIMENTO - PNUD. PNUD explica transição dos Objetivos do Milênio aos Objetivos de Desenvolvimento Sustentável, 08 dez. 2015. Disponível em: <https://nacoesunidas.org/pnudexplica-transicao-dos-objetivos-do-milenio-aos-objetivos-de-desenvolvimentosustentavel/>. Acesso em: 22 nov. 2017.

ROCASOLANO, Maria Mendez; SILVEIRA, Vladmir Oliveira da. Direitos humanos: conceitos, significados e funções. São Paulo: Saraiva, 2010.

SALMÓN G., Elizabeth. O longo caminho da luta contra a pobreza e seu alentador encontro com os direitos humanos. Sur: Revista Internacional de Direitos Humanos, São Paulo, v. 4, n. 7, p. 152-167, 2007. Disponível em: < http://www.scielo.br/scielo. php?pid $=$ S1806-64452007000200007\&script $=$ sci_abstract\&tlng $=$ pt $>$. Acesso em: 21 nov. 2017.

SANTOS, Boaventura de Sousa. A gramática do tempo: para uma nova cultura política. São Paulo: Cortez, 2006.

SANTOS, Boaventura de Sousa. Os direitos humanos na pós-modernidade. Oficina do CES, Coimbra, n. 10, p. 1-14, jun. 1989. Disponível em: < http://www.ces.uc.pt/ myces/UserFiles/ivros/1097_Oficina\%20do\%20CES_10.pdf>. Acesso em: 14 nov. 2017. 
do Milênio. Disponível em: <https://www.unicef.org/brazil/pt/resources_9540. htm >. Acesso em: 22 nov. 2017.

ORGANIZAÇÃO DAS NAÇÕES UNIDAS - ONU. Cúpula das Nações Unidas sobre o Desenvolvimento Sustentável: Transformar nosso mundo para as Pessoas e o Planeta, 2017a. Disponível em: <https://nacoesunidas.org/pos2015/cupula/>. Acesso em: 15 nov. 2017.

ORGANIZAÇÃO DAS NAÇÕES UNIDAS - ONU. Momento de ação global para as pessoas e o planeta, 2017b. Disponível em: < https://nacoesunidas.org/pos2015/>. Acesso em: 21 nov. 2017.

ORGANIZAÇÃO DAS NAÇÕES UNIDAS - ONU. Objetivos de Desenvolvimento Sustentável da ONU completam 2 anos, 25 set. 2017c. Disponível em: < https:// nacoesunidas.org/objetivos-de-desenvolvimento-sustentavel-da-onu-completam-2anos/>. Acesso em: 21 nov. 2017.

ORGANIZAÇÃO DAS NAÇÕES UNIDAS - ONU. Principais fatos, 2017d. Disponível em: < https://nacoesunidas.org/pos2015/principais-fatos/>. Acesso em: 20 nov. 2017.

ORGANIZAÇÃO DAS NAÇÕES UNIDAS - ONU. Roteiro para a Localização dos Objetivos de Desenvolvimento Sustentável: Implementação e Acompanhamento no nível subnacional, 2016. Disponível em: < https://nacoesunidas.org/wp-content/ uploads/2017/06/Roteiro-para-a-Localizacao-dos-ODS.pdf $>$. Acesso em: 21 nov. 2017.

ORGANIZAÇÃO DAS NAÇÕES UNIDAS - ONU. Transformando Nosso Mundo: A Agenda 2030 para o Desenvolvimento Sustentável, 2015. Disponível em: < https:// nacoesunidas.org/wp-content/uploads/2015/10/agenda2030-pt-br.pdf > . Acesso em: 12 nov. 2017.

ONU MULHERES, Entidade das Nações Unidas para a Igualdade de Gênero e o Empoderamento das Mulheres. Declaração e Programa de Ação de Viena, 1993. Disponível em: <http://www.onumulheres.org.br/wp-content/uploads/2013/03/ declaracao_viena.pdf $>$. Acesso em: 23 de nov. 2017. 